\title{
BETEMBANG PADA TARI ADAT DALAM BIMBANG PERNIKAHAN SUKU LEMBAK
}

\author{
'Nadila Rizky Pratiwi; ${ }^{2}$ Sarwit Sarwono; ${ }^{3}$ Agus Joko Purwadi \\ 1,2,3 Program Studi Pendidikan Bahasa Indonesia FKIP Universitas Bengkulu
}

Abstrak

\section{Korespondensi: nadila436@yahoo.co.id}

Tujuan penelitian ini untuk memahami dan menjelaskan betembang pada tari adat dalam bimbang pernikahan suku Lembak. Metode penelitian yang digunakan adalah kualitatif etnografi. Lokasi penelitian dilakukan di Kecamatan Kota Padang dan Kecamatan Binduriang. Teknik pengumpulan data dilakukan dengan cara observasi terhadap pertunjukan betembang dan konteks sosial masyarakat Lembak, wawancara terhadap informan yang memiliki informasi tentang betembang dan dokumentasi yang berupa foto dan video yang berhubungan dengan betembang. Teknik analisis data dilakukan dengan menafsirkan data, fenomena atau peristiwa betembang. Hasil penelitian ini adalah betembang dilaksanakan pada hari ngatat dendan dan hari sedekah. Alat musik yang digunakan adalah kenong 6 buah/ kenong 12, atau gendang, gong, kolintang, redap dan biola. Tembang memiliki makna bahwa tuan rumah memberikan penghormatan terhadap tamu yang hadir. Selain itu tembang juga berisi sindiran, lelucon dan kesedihan terhadap kondisi sosial masyarakat Lembak.

Kata kunci: betembang, kualitatif etnografi, suku lembak

\section{Abstract}

The purpose of this study was to understand and explain the betembang as traditional dance in the bimbang of the Lembak tribe marriage. The research method used is qualitative ethnography. The data in this study are the bimbang texts, documentation, observations, and interviews. The source of the data from this study is an informant who has information about the tradition of betembang a traditional dance in the bimbang of the Lembak tribe marriage. The location of the study was conducted in Kota Padang District and Binduriang District. Data collection techniques are carried out by observation, interviews and documentation. Data analysis techniques are done by interpreting data in the form of events and phenomena of the betembang tradition as traditional dance in the bimbang of the Lembak tribe marriage. The results of this study are to understand the text of the Betembang is held on atat endan days and sadaqah days. The musical instruments used are kenong 6 pieces / kenong 12, or drum, gong, kolintang, redap and violin. Tembang means that the host respects guests. Besides that, the song also contains satire, jokes and sadness towards the social conditions of the people of Lembak.

Keywords: betembang, qualitative ethnography, lembak tribe 


\section{PENDAHULUAN}

Suku Lembak adalah suku bangsa yang permukimannya tersebar di Kota Bengkulu, Kabupaten Bengkulu Utara, Kabupaten Bengkulu Tengah, Kabupaten Rejang Lebong, Kabupaten Kepahiang. Suku Lembak di Kabupaten Rejang Lebong bermukim di Kecamatan Padang Ulak Tanding, Kecamatan Sindang Kelingi, Kecamatan Kota Padang, Kecamatan Sindang Beliti Ulu, Kecamatan Sindang Beliti Ilir dan Kecamatan Binduriang. Di Kabupaten Kepahiang, suku Lembak mendiami Desa Suro Lembak. Suku Lembak juga mendiami Kota Lubuk Linggau dan Kabupaten Musi Rawas yang berada di Provinsi Sumatera Selatan. Suku Lembak yang mendiami Kabupaten Rejang Lebong disebut suku Beliti, sedangkan suku Lembak yang mendiami Kabupaten Bengkulu Tengah dan Kota Bengkulu disebut suku Lembak Delapan yang terbagi tiga, yaitu suku Lembak Bulang, suku Lembak Tanjung Agung dan suku Lembak Pedalaman (Oktarina, 2013:26).

Mata pencaharian utama masyarakat Lembak adalah bertanam padi di sawah, sayur-sayuran dan buah-buahan di ladang. Tanahnya yang subur cocok pula dijadikan kebun kopi, cengkeh dan lada. Sebagian lain bekerja sebagai pedagang, tukang kayu dan sebagainya. Pekerjaan bertani umumnya masih dikerjakan secara gotong-royong dan bermusim.

Selain kaya akan hasil pertanian, suku Lembak juga merupakan salah satu suku yang memiliki kebudayaan yang cukup banyak dan unik. Menurut Koentjaraningrat (1989:9), kebudayaan adalah sebagai keseluruhan gagasan dan karya manusia yang harus dibiasakannya dengan belajar, beserta keseluruhan dari hasil budi dan karyanya itu. Salah satunya adalah tradisi pernikahan. Masyarakat Lembak menganggap bahwa penikahan adalah suatu peristiwa yang bersifat sakral. Selama prosesi pernikahan, terdapat tari adat yang biasa ditarikan. Tarian tersebut adalah tari senjang.

Pada Tari senjang terdapat hal yang menarik yaitu adanya nyanyian/ syair yang mirip dengan pantun yang disebut tembang. Tembang merupakan salah satu bentuk folklor yang dimiliki oleh masyarakat Lembak. Kehadirian tembang tentunya tidak terlepas dari tari senjang. Berdasarkan bentuk folkor, betembang dan tari senjang dapat dikelompokkan menjadi folkor sebagian lisan. Hal ini disebabkan oleh bentuknya yang merupakan perpaduan antara unsur lisan dan unsur bukan lisan.

Berdasarkan bentuknya folklor dibagi menjadi 3, yaitu folklor lisan yang berbentuk murni lisan, folklor sebagian lisan yang merupakan campuran unsur lisan dan bukan lisan, dan folklor bukan lisan yang bentuknya bukan lisan, walaupun pembuatannya diajarkan secara lisan (Danandjaja, 1994:22). Unsur lisan yang berada pada tradisi betembang terdapat pada lantunan tembang yang dinyanyikan, dan tari menjadi unsur bukan lisannya yang berupa perpaduan gerakan-gerakan yang menghasilkan sebuah pola gerak yang indah.

Perpaduan antara tari senjang dan betembang akan membentuk suatu seni pertunjukan yang menarik bagi masyarakat Lembak, sehingga betembang dapat dinikmati melalui sebuah seni pertunjukan. Menurut Liliweri (2014:326), seni pertunjukan adalah seni yang ditampilkan menggunakan gerak tubuh atau suara untuk menyampaikan ekspresi jiwa pemainnya.

Di dalam tembang tersimpan keunikan yang membedakan dengan seni yang lainnya. Mulai dari pemilihan katanya yang khas yaitu menggunakan bahasa Lembak, hingga pada pemaknaannya yang dapat menggambarkan keadaan sosial masyarakat Lembak serta mengandung pesan moral. 
Oleh karena itu, pemaknaan mengenai betembang dapat dipahami dan dijelaskan melalui ilmu sosipragmatik. Sosiopragmatik merupakan gabungan dari dua cabang ilmu, yaitu bidang sosial dan bidang pragmatik. Menurut Gunarwan (1994:83), kajian sosiopragmatik adalah penelitian yang memusatkan kajiannya pada language use, bukan language usage, di dalam sebuah masyarakat budaya di dalam situasi sosial tertentu, sehingga maksud tuturan perlu diperhatikan dari segi siapa berbicara kepada siapa, di mana, untuk apa, bilamana, bagaimana, tentang apa, dan sebagainya yang dikaitkan dengan masyarakat sosial tertentu ke dalam wadah kajian sosiopragmatik.

Dewasa ini, tari senjang dan betembang sangat jarang ditemukan di suku Lembak. Hal ini disebabkan oleh, perkembangan zaman dan teknologi yang semakin pesat, sehingga tradisi seperti ini tidak diminati dan perlahan mulai menghilang.

Penelitian mengenai tradisi berpantun pada tari adat dalam bimbang pernikahan juga pernah dilakukan oleh Alamsyah pada tahun 1995 yang berjudul Unsur Didaktis Seramba dalam Acara Tari Lembak Delapan, Tafsili tahun 2018 yang berjudul Kreasi Tari Gandai Kecamatan Marga Sakti Sebelat Kabupaten Bengkulu Utara Provinsi Bengkulu, dan Cangga tahun 2018 yang berjudul Pantun pada Seni Pertunjukan dalam Adat Pernikahan di Kecamatan Kaur Selatan Kabupaten Kaur.

Berdasarkan hal ini maka muncul masalah yaitu mengenai pemaknaan betembang pada tari adat dalam bimbang pernikahan suku Lembak, sehingga penelitian ini bertujuan untuk memahami dan menjelaskan tradisi betembang pada tari adat dalam bimbang pernikahan suku Lembak yang akan bermanfaat untuk sumber ilmu pengetahuan dan rujukan bagi penelitian selanjutnya. Selain itu, penelitian ini dapat juga dimanfaatkan sebagai cara menambah pemahaman masyarakat setempat terhadap folklor yang mereka miliki agar dijaga dan dilestarikan.

\section{METODE}

Metode penelitian yang digunakan dalam penelitian ini adalah metode penelitian kualitatif etnografi. Data dalam penelitian ini adalah teks tembang, hasil dokumentasi, hasil pengamatan, dan hasil wawancara terhadap informan mengenai tradisi betembang pada tari adat dalam bimbang pernikahan masyarakat Lembak.

Sumber data pada penelitian ini berasal dari kegiatan observasi (pengamatan langsung), kegiatan mendokumentasi, dan kegiatan wawancara terhadap informan yang memiliki informasi mengenai tradisi betembang di suku Lembak.

Penelitian dilakukan di Desa Kepala Curup, Kecamatan Binduriang dan Kelurahan Kota Padang, Kecamatan Kota Padang.

Teknik pengumpulan data yang digunakan dalam penelitian ini adalah observasi, wawancara, dan dokumentasi. Analisis data dilakukan dengan cara antara lain: 1. Menyalin kembali hasil dari pengamatan, wawancara, dokumentasi dan catatan lapangan ke dalam catatan. 2. Mengelompokkan data yang dibutuhkan sesuai dengan objek penelitian. 3. Menerjemahkan data tentang tradisi betembang dari bahasa asli (bahasa Lembak) ke dalam bahasa Indonesia. 4. Mengolah data dengan memaknai tradisi betembang dengan menggunakan teori sosio pragmatik. 5. Meninjau atau mengembalikan hasil dari pengolahan data penelitian kepada informan. 6. Membuat kesimpulan dan saran-saran yang berhubungan dengan tembang dan prosesnya. 


\section{HASIL PENELITIAN DAN PEMBAHASAN}

Pada upacara pernikahan, suku Lembak biasanya melakukan berbagai prosesi adat. Salah satunya adalah hari atat endan dan hari sedekah. Hari atat endan adalah salah satu prosesi pernikahan yang sangat ditunggu-tunggu oleh kedua mempelai, karena pada hari itu kedua mempelai akan mengucapkan janji suci di depan penghulu dan masyarakat. Prosesi atat endan akan dilakukan dengan tunang bersama keluarga datang menuju ke rumah menyan untuk melakukan ijab Kabul, sedangkan pada hari sedekah masyarakat akan berdo'a bersama untuk mendoakan kedua mempelai. Pada hari tersebut biasnaya akan ditampilkan tarian senjang dan betembang.

Betembang dan tari senjang dapat dilakukan pada hari atat endan maupun hari sedekah bergantung dengan permintaan tuan rumah. Betembang adalah sebuah kegiatan yang hampir mirip dengan berpantun. Menurut KBBI, tembang adalah syair yang diberikan lagu (untuk dinyanyikan). Betembang biasanya ditampilkan bersamaan dengan tari senjang. Alat musik tradisional yang pertama digunakan untuk mengiringi tari senjang adalah kenong 6 buah / kenong 12. Selain itu, tarian senjang dan betembang juga dapat diiringi beberapa alat musik lain seperti biola, gendang, tamborin (disebut cekcer oleh orang Kota Padang), akordion dan gong. Ketika ada acara pernikahan, penari biasanya mengenakan pakaian yang memiliki warna yang seragam. Mulai dari baju kebaya yang bikat (pendek bawahnya) ataupun kebaya kurung, kain bawahan, kain songket, dan selendang/ rebang.

Tari senjang memiliki gerakan ngibang/ menggoyangkan selendang dengan lembut ke kiri dan ke kanan yang menjadi simbol penyambutan terhadap tamu undangan sekaligus untuk mempersilahkan tamu undangan untuk masuk dan duduk. Gerakan inilah yang menyebabkan tari senjang dan betembang sering dibawakan di awal acara.

Tidak ada syarat khusus untuk menjadi seorang penembang. Penembang tidak dibatasi jumlah, maupun jenis kelaminnya. Namun, saat ini kebanyakan orang yang bisa betembang adalah orang yang sudah tua. Berumur sekitar 50 tahun ke atas. Terkadang penembang bisa saja ditunjuk ataupun atas kemauan sendiri dan penari pun bisa saja ikut betembang. Kebanyakan penembang adalah orang yang berbeda

Pada kenyataannya, menembang biasanya bisa dilakukan hanya sendirian saja. Penonton terkadang ada juga yang ingin ikut betembang, sehingga jumlah penembang dapat saja bertambah ketika pertunjukan sedang berlangsung.

Tembang yang dibawakan biasanya berisi mengenai permohonan izin untuk menari, kondisi sosial masyarakat saat itu, dan penutup. Tidak begitu banyak tembang yang biasa dilantunkan pada sekali pertunjukan. Biasanya penembang hanya melantunkan 4-6 tembang setiap kali tampil, sehingga ada 8-12 kali betembang karena untuk satu tembang akan dinyanyikan dalam dua bagian.

Tembang pada tari senjang memiliki struktur yang hampir sama dengan pantun. Baris pertama dan kedua hampir mirip dengan sampiran, baris ketiga dan keempat bisa pula disebut isi. Tembang bisanyanya dibagi menjadi tiga baigain, yaitu tembang pembuka, tembang isi dan tembang Penutup.

Tembang yang ada pada tari senjang cukup bervariasi, hal ini terjadi karena tembang yang dimiliki oleh setiap penembang berbeda-beda. Namun, ada beberapa isi tembang yang mirip dan bahkan ada yang sama. Ada sebuah tembang yang menjadi ciri khas dari tari senjang. Setiap kali menari, tari senjang akan dibuka dengan sebuah tembang tang lapek Versi ini muncul karena adanya perbedaaan usia dan asal daerah penembang

Berikut beberapa tembangnya: 
1. (a) Tang lapek selonjo doson Ati mengolet anak lang Mitek setabek ketue doson Kami nupang nari senjang

(b) Betang lapek sepanjang rumah Prati ngolet anak lang Setabek tue di rumah Gadis kesian mupang senjang

Kata tang lapek yang dipakai di awal tembang pembuka menyimbolkan bahwa lapek dalam bahasa Lembak berarti alas/ dasar/ pondasi. Alas, dasar atau pondasi yang pada dasarnya diletakkan pertama kali ketika akan memulai sesuatu. Sama halnya dengan tembang tang lapek, yang selalu dijadikan tembang pembuka untuk memulai betembang dan menari senjang. Kemudian, ketika alas telah dibentangkan maka seseorang biasanya akan memohon izin terlebih dahulu untuk melanjutkan hajatnya, yaitu menari senjang yang dapat dilihat dari kata "mitek setabek ketue doson" (mitek izin ketua dusun), "kami nupang nari senjang" (kami menumpang menari senjang). Kata ketue dusun tidak hanya berarti kepala desa, tetapi juga orang-orang terhormat lainnya, seperti ketua adat, ketua BMA, para pejabat pemerintahan dan sebagainya. Pada acara pernikahan, permohonan izin diucapkan sebagai bentuk penghormatan kepada tuan rumah dan tamu undangan sekaligus pemberitahuan bahwa akan ditampilkan sebuah tari senjang

Setelah penembang selesai mengucapkan tembang pembuka seperti tembang tang lapek, maka penembang akan menembang sesuai dengan tembang yang ingin ia sampaikan. Terkadang tembang yang disampaikan berisi kondisi sosial masyarakat saat itu, suka duka kehidupan, maupun berupa sindirian dan nasihat. Semuanya bergantung dengan sang penembang. Tembang tersebut antara lain:

2. (a) Name upek mobel wang mupe

Mbay padeti degi modek sampai mupe ngambur jele

Tari senjang tarian lame

Men dak diingat mapos gele

Maksud dari tembang ini hampir sama yaitu pemberitahuan kepada khalayak ramai bahwa tari sejang adalah sebuah tarian lama yang telah ada pada zaman nenek moyang dahulu, dan jika tidak diingat dan dilestarikan maka tradisi ini akan menghilang/ punah. Hal ini sejalan dengan keyakinan masyarakat bahwa tari senjang tergolong ke dalam tarian lama masyarakat Lembak yang sangat disayangkan jika mengalami kepunahan.

Oleh karena itu, pada tembang ini tersirat pesan bahwa masyarakat haruslah mengingat dan melestarikan tarian-tarian lama karena jika tidak maka keberadaannya akan perlahan menghilang dan tergantikan oleh hiburan-hiburan modern yang sedang berkembang saat ini.

(b) Tekoyong umban dilocak Alangke ladas biti mandi 


\title{
Nadila; Sarwit Sarwono; Agus Joko Purwadi
}

\author{
Laju keleton mandi pule \\ Kalo ibuk-ibuk nari pacak \\ Alang ka ladas asek kami \\ Laju wang noton rami pule
}

Maksud dari kedua tembang ini adalah untuk menyampaikan bahwa penari dan penembang ikut bahagia ketika dapat menarikan tarian senjang dan betembang. Wujud rasa bahagia menyambut kedatangan tamu undangan dalam pernikahan ini diutarakan melalui sebuah tarian dan tembang

(c) Ibti tun bekulei

Uje wang Rejang ndaki boket

Hame-hame tohon ke Lembak Lobok. Aman

Kalau seni niru care adat

Reski tohon dari langet

Negri makmur jedi aman

Tembang ini mengandung makna yang mendalam, penembang yang mewakili pandangan sosial masyarakat Lembak menyampaikan bahwa ketika sebuah seni berpedoman pada adat/ aturan masyarakat setempat maka tuhan akan menurunkan rezeki yang berlimpah, sehingga negeri akan makmur dan aman. Hal ini menunjukkan bahwa adat adalah sebuah pedoman hidup yang perlu ditaati oleh masyarakat. Ketika kehidupan telah berpedoman pada adat, maka kehidupan akan berjalan dengan baik, sehingga tuhan akan memberikan rezeki kepada hambanya dan menjadikan negeri menjadi makmur dan aman serta terbebas dari masalah.

(d) Anak cicak anak wakuwe

Anak biti kayo mandi

Edu mandi besa gele

Benyak licak awak la tue

Notot jelan susah ati

Anak la cocong ngimak gele

Tembang ini juga berisi tentang sindiran kepada orang yang sudah tua yang perilakunya seperti anak muda. Perilaku mereka tidak mencerminkan usia, sehingga anakanak ngimak/ mengolok-olok perilaku orang tua yang sering mabuk-mabukan ataupun mengikuti acara tua-tui, karena tidak sepantasnya orang yang sudah tua banyak tingkah/ licak seperti anak muda. Ketika malam hari, mereka lebih baik menghabiskan waktu bersama keluarga di rumah ataupun bergaul sesama orang tua dan tidak perlu melakukan hal-hal yang tidak berguna seperti itu. Acara tua tui adalah acara hiburan yang dilakukan pada malam hari pada acara pernikahan zaman sekarang.

(e) Kekebon jelan kebek-kebek

Nemu imbe pacat gele

Temu bedugam beruge aghai malam

Rusak ajor adat wang tue 
Tua tui joget gele

Bujang dehe ngelong malam

Tembang ini adalah kelanjutan dari tembang sebelumnya yang menyiratkan sindirian/ keprihatinan kaum tua terhadap kondisi masyarakat saat ini. Pada zaman dahulu adat/ aturan nenek moyang sangat dijunjung tinggi. Begitu pula pada pergaulan anak-anak dan remaja yang sangat dijaga/ dibatasi. Pada saat ini adat/aturan tersebut telah rusak dan mengalami banyak perubahan. Anak-anak dapat bergaul bebas dengan lawan jenis. Bahkan ketika ada acara pernikahan, sering kali diadakan acara tua tui pada malam hari.

Pada acara ini terjadi kehancuran moral pada muda-mudi, orang tua dan anakanak. Orang tua yang seharusnya menjadi panutan, malah memberikan contoh yang tidak baik. Pada acara tersebut biasanya orang-orang yang datang akan berjoget bersama dan minum-minuman keras. Tidak ada lagi batasan pergaulan. Bujang dan gadis bebas berkeliaran pada malam hari. Hal ini sangat kontras dengan adat orang tua zaman dahulu

Selain membahas mengenai isu-isu sosial masyarakat, betembang juga menjadi sarana untuk mencurahkan isi hati penembangnya, baik kesedihan maupun kebahagiaan. Berikut ini beberapa tembang kesedihan yang dibawakan oleh beberapa penembang.

(f) Benyak tebu totong menotong

Cuman seruas tebu lalang

Benyak kundu serempak toron

Cuman ku burang toron malang

Tembang di atas mengandung makna bahwa banyak sekali manusia yang lahir ke dunia, tetapi hanya dia seorang yang bernasib malang. Tembang ini dibuat oleh seorang penembang yang kehidupannya mengalami kemalangan. Semenjak kecil kedua orang tuanya meninggal dunia, dan ia harus tinggal bersama nenek yang sudah tua dan bekerja hanya sebagai seorang petani. Selain itu, tembang ini juga mengandung makna bahwa setiap manusia dilahirkan ke dunia dengan membawa takdirnya masing-masing, baik itu berupa kesedihan/ kemalangan hidup maupun kebahagiaan. Ketika mendengarnya penonton akan merasa kasihan dan bahkan dapat meneteskan air mata.

(g) Ku tau ayek ngerawang

Ape ku nyabon diberang sana

Ku tau sukatku malang

Ngape ku toron dalam dunia

Tembang ini mengandung makna bahwa jika kehidupan ini berisi kemalangan, maka untuk apa dilahirkan ke dunia. Ini menunjukkan bahwa munculmya sebuah penyesalan/ kemarahan atas keadaan hidup yang telah dialami. Tembang ini disampaikan sebagai bentuk penyesalan sekaligus nasihat kepada penonton bahwa ketika kita memiliki sebuah masalah, kita haruslah tetap bersyukur dan tidak mengeluh karena sesungguhnya masih banyak orang yang lebih susah dibandingkan dengan kita. Selain itu, tembang ini juga mengajak penonton untuk merasakan kesedihan dan kepahitan hidup yang dialami oleh penembangnya. 
Bagi pengantin, tembang ini mengisyaratkan makna bahwa dalam kehidupan berumah tangga kelak, pasti dihadapkan pada berbagai masalah kehidupan dan tidak ada yang bisa menjamin bagaimana kehidupan setelah menikah. Oleh sebab itu, kita harusnya dapat mempersiapkan diri atas segala kemungkinan yang ada dan terus selalu bersyukur atas segala yang telah terjadi.

Ketika berbagai tembang telah dinyanyikan, maka pertunjukan tari senjang juga akhiri dengan tembang penutup. Terdapat beberapa tembang yang biasa dibawakan penembang untuk menutup penampilan mereka. Tembang tersebut antara lain:

\section{3. (a) Malam ini malam selikor \\ Besok pagi tiga puluh \\ Hari ini kita becampor \\ Besok pagi melayang jauh}

Kata becampur, pada tembang di atas menyiratkan makna "bersama-sama". Pada acara pernikahan, keluarga akan berkumpul untuk merayakan pernikahan kedua mempelai. Namun, setelah acara selesai satu per satu keluarga akan pulang dan melanjutkan rutinitas masing-masing.

Selain itu, biasanya setelah menikah pengantin wanita akan dibawa pengantin lakilaki untuk ikut bersamanya dan berpisah dengan keluarga, sehingga tembang ini sebagai bentuk ungkapan perpisahan kepada keluarga. Bagi penembang tembang ini sebagai bentuk ucapan perpisahan terhadap penonton yang telah menyaksikan pertunjukan mereka.

\section{PENUTUP}

Berdasarkan hal tersebut maka pertunjukkan Betembang pada masyarakat Lembak umumnya dilaksanakan pada hari ngatat dendan dan bisa pula pada hari sedekah, tepatnya pada siang hari. Tradisi betembang biasanya disertai dengan tari senjang dan diiringi oleh alat musik tradisional seperti kenong 6 buah atau kenong 12, biola, gendang, tamborin (cekcer), akordion, dan gong. Namun, saat ini betembang diiringi oleh organ tunggal saja. Pertunjukkan betembang yang ditampilkan pada acara pernikahan memiliki makna bahwa tuan rumah memberikan penghormatan terhadap tamu yang hadir. Selain itu, betembang juga bermakna sindiran, lelucon hingga kesedihan terhadap kondisi sosial masyarakat saat itu. Oleh karena itu, tembang terdapat nilai moral yang ingin disampaikan kepada penontonnya baik itu kepada kedua mempelai maupun masyarakat umum. Pertunjukkan betembang yang dilaksanakan pada acara pernikahan juga menjadi salah satu cara untuk melestarikan tradisi yang dimiliki oleh masyarakat Lembak agar tidak punah.

Keberadaan pertunjukan betembang pada masyarakat Lembak sudah sangat sulit ditemukan. Oleh karena itu, pertunjukan betembang perlu dilestarikan oleh seluruh masyarakat khususnya para generasi muda baik melalui berbagai cara seperti pada acara pernikahan, penyambutan bupati dan sebagainya agar tidak mengalami kepunahan. Selain itu, diharapkan adanya penelitian lanjutan pada tradisi-tradisi lain yang dimiliki oleh masyarakat Lembak karena masih banyaknya tradisi-tradisi yang masih hidup yang dapat digali lebih dalam lagi. 


\section{DAFTAR PUSTAKA}

Danandjaja, J. 1994. Folklor Indonesia Ilmu Gosip, Dongeng, dan Lain-lain. Jakarta: Pustaka Utama Grafity.

Gunarwan, Asim. 1994. "Kesantunan Negatif di Kalangan Dwibahasawan Indonesia-Jawa di Jakarta: Kajian Sosiopragmatike” dalam PELLBA Jakarta: Pusat Kajian Bahasa dan Budaya Unika Atmajaya.

Koentjaraningrat. 1989. Sejarah Teori Antropologi I. Jakarta. Universitas Indonesia.

Liliweri, Alo. 2014. Pengantar Studi Kebudayaan. Bandung. Penerbit Nusa Media.

Oktarina, Haryani. 2013. Kesenian Sarafal Anam dan Nilai-nilai yang Terkandung didalamnya pada Masyarakat Lembak dalam Adat Istiadat. Skripsi. Bengkulu: Fakultas Ilmu Sosial Dan Ilmu Politik Universitas Bengkulu. 